\title{
LUT
}

University

\section{User motivation and knowledge sharing in idea crowdsourcing}

Kosonen Miia, Gan Chunmei, Vanhala Mika, Blomqvist Kirsimarja

This is a Final draft

version of a publication

published by Imperial College Press

in International Journal of Innovation Management

DOI: $10.1142 / S 1363919614500315$

Copyright of the original publication: (c) Imperial College Press

Please cite the publication as follows:

Kosonen, M., Gan, C., Vanhala, M., Blomqvist, K. (2014). User motivation and knowledge sharing in idea crowdsourcing. International Journal of Innovation Management, vol. 18, issue 5.

DOI: $10.1142 / S 1363919614500315$

This is a parallel published version of an original publication.

This version can differ from the original published article. 


\section{User motivation and knowledge sharing in idea crowdsourcing}

\section{Introduction}

Both researchers and practitioners are making increasing efforts to understand how to harness consumers' valuable knowledge in the innovation process. Companies that facilitate consumer participation in new product development may gain a competitive advantage over traditional companies that do not empower their users and consumers (Fuchs and Schreier, 2011). User participation in both the front end phase of product development (idea generation, concept) and the back end (design and testing) is seen as enhancing innovation (Füller et al., 2006; Nambisan and Baron, 2007; Sawhney et al., 2005). For instance, online communities (OCs) allow companies to interact directly with consumers and integrate a large mass of product users together, while potentially making them co-innovators (Faraj et al., 2011; von Hippel et al., 2011; Nambisan and Baron; 2007, 2009; Sawhney et al., 2005). Another recent illustration of a co-innovative activity is crowdsourcing, where an organization seeks input from volunteer users. Yet the innovative input calls for people who actively participate in sharing and creating knowledge.

While crowdsourcing may have been around for a long time, the advent of communication technologies has catalyzed the phenomenon (Afuah and Tucci, 2012, Simula and Vuori, 2012). Crowdsourcing can be defined as "the act of taking a task traditionally performed by a designated agent (such as an employee or a contractor) and outsourcing it by making an open call to an undefined but large group of people" (Howe, 2008). Crowdsourcing could be seen as one method of co-creation (Prahalad and Ramaswamy, 2000), user innovation (von Hippel, 1988), and more broadly, open innovation (Chesbrough, 2003). Existing studies clearly indicate that crowdsourcing has the potential to contribute significantly to innovation. For instance, Poetz and Schreier (2012) found that ideas stemming from consumers scored higher in terms of novelty and customer benefit than ideas generated by professionals. They also point out how attracting the right people is crucial for the success of any crowdsourcing activity. When studying company-hosted crowdsourcing initiatives, it is of particular importance to consider the appropriate incentive mechanisms, and in broader terms, what ultimately motivates users to contribute.

However, prior research on the motivation to share knowledge in the specific context of idea crowdsourcing is scarce (see Zheng et al., 2011 for an exception). We focus our investigation on the idea generation phase of the innovation process. Other types of crowdsourcing activities such as crowd-funding or assigning routine tasks to a large mass of users (e.g. Brabham, 2010) are also excluded. In idea crowdsourcing, there is a hosting organization looking to benefit from the new product ideas or designs suggested by voluntary users. We acknowledge that in online-community settings there is already a body of research concerning motivation to participate, such as that relating to open source software communities (Hars and Ou, 2002; Hertel et al., 2003; Roberts et al., 2006), firm-hosted travel communities (Cásalo et al., 2010), communities of music hobbyists (Jeppesen and Frederiksen, 2006) and online professional networks (Wasko and Faraj, 2005). Intrinsic motivations, such as enjoyment, being able to help others and develop better products, largely seem to drive participation in 
OCs dedicated to software development (Bagozzi and Dholakia, 2006; Wasko and Faraj, 2000) or designing sports equipment, for example (Füller et al., 2006, Jawecki et al., 2011).

While we believe it is important to recognize the findings from current research on knowledge-sharing motivations in OCs, we argue there is a need to understand the sharingintentions outside OCs that are clearly focused on a specific niche interest. First, in idea crowdsourcing, voluntary users typically act on the basis of their own prevailing interest, instead of having a shared interest that unites a group of users into a community. Secondly, OCs are by nature collaborative, whereas idea crowdsourcing can be competitive, collaborative, or both simultaneously (Hutter et al., 2011). Such features make idea crowdsourcing an intriguing area of study in terms of why and how users engage in knowledge-sharing activities. Therefore, the current research investigates how the propensity to trust, intrinsic motivation, and extrinsic motivation drive the intentions of individuals to share knowledge in firm-hosted idea crowdsourcing settings. Furthermore, the study questions whether the intention to share knowledge manifests itself as actual knowledge-sharing behaviour.

This paper is organized as follows. Section 2 introduces the conceptual background and sets out our hypotheses. In section 3, we explain the research methodology applied in the empirical part of the study. We report the results in section 4. Finally, we discuss the implications of the study and identify some potential avenues for further research.

\section{Theoretical background}

Building on motivation theories and Uses \& Gratifications (U\&G) approach, in this section we introduce the concepts of propensity to trust, intrinsic motivation and extrinsic motivation, and discuss their role in 1) forming individual intentions to share knowledge and 2) the actual knowledge-sharing behaviour, in the light of current research.

\section{Propensity to trust}

Propensity to trust is defined as the general expectancy of trust based on individual socialization (McKnight et al., 1998; Rotter, 1967) and personality (Colquitt et al., 2007). An individual's propensity to trust has an impact on how that individual is willing to trust others, and how they experience trust (Rotter, 1967). Propensity to trust is assumed to be relatively more salient when the interacting parties are less familiar with each other and do not yet have sufficient information to cognitively evaluate each other's trustworthiness (Mayer et al., 1995). It is thus a relevant concept for knowledge sharing in crowdsourcing where users do not know each other personally, and its role is assumed to be relatively more salient in the early phases of user involvement (see also, Ridings et al., 2002).

Furthermore, the propensity to trust is seen to vary across cultures (Dietz et al, 2010; Hofstede, 1991). For instance, Yang et al. (2011) found out that in a Chinese online community, users engaged in behaviour typical of that culture, namely, the social use of personal networks of reciprocal obligation known as guanxi. However, in loose online collectives, such personal networks do not necessarily evolve, as people only come and go based on their own interests. In such settings, it is necessary to explore individual users' propensity to trust, that is, the general trusting attitude. 


\section{Intrinsic motivation}

In general, motivation is a psychological state, whereas behaviour represents the outcome of that state (Mitchell and Daniels, 2003). Motivations affect the nature of an individual's behaviour, the strength of the behaviour, and its persistence. A common conceptualization of motivation is based on its origins, being either intrinsic or extrinsic in nature. Intrinsic motivation refers to situations where an activity is likely to be performed for its own sake, rather than as a means to an end (Deci and Ryan, 2000). It is thus related to activities that satisfy basic human needs for competence, control and autonomy. It is important to distinguish the motivation from the actual behaviour (Roberts et al., 2006). Motivation focuses attention on particular task elements, implying that motivated people dedicate more effort to that task.

A closely related issue is the 'uses and gratifications' (U\&G) approach (Katz et al., 1974). While a variety of motivation factors have been identified across different types of OCs, such as acquiring valuable knowledge (Wasko and Faraj, 2005), the enjoyment of helping others (Wasko and Faraj, 2000), improving status (Roberts et al., 2006) or gaining recognition from peers (Jeppesen and Frederiksen, 2006), it is important to note that these factors could be mapped within the broader categories identified in the U\&G approach. The categories are based on the internal and external benefits people expect from certain actions. Cognitive/learning benefits relate to acquiring information and improving one's learning opportunities, while social integrative benefits deal with the opportunity to strengthen ties with relevant others, for example through establishing online-community relationships. Hedonic benefits are related to situations that are able to provide aesthetic or pleasurable experiences to the user (Katz et al., 1974; Nambisan and Baron, 2009). Online-community participation may for example provide opportunities for enjoyable experiences by providing fun or pleasurable experiences on the one hand, and by providing mentally or intellectually stimulating interactions on the other.

\section{Extrinsic motivation}

Extrinsic motivation can be conceptualized as performing a certain activity in order to achieve an outcome (e.g., reward) stemming from external sources (Ryan and Deci, 2000). It is seen as contrasting with intrinsic motivation, as people may shift their attention to the reward in question and a prior intrinsic motivation does not return even if no further incentives are offered. As Roberts et al. (2006) point out, it is important to assess how the different forms of motivations relate to each other, because it is the participant's set of motivations together with their knowledge, skills and abilities that produce the participant's behaviours and performance. In this study, we therefore examine both types of motivations in parallel.

Within the U\&G approach (Katz et al., 1974), personal integrative benefits are related to strengthening an individual's status, credibility and confidence. Personal integrative benefits imply achieving self-efficacy, that is, influencing the surrounding collective. For instance, members may improve their personal status and reputation by sharing valuable knowledge with others. Acting to achieve such a personal integrative outcome can thus be seen as a manifestation of extrinsic motivation. In Deci and Ryan's terms (2000), status and career 
opportunities lie between the intrinsic and extrinsic, in that they constitute internalized extrinsic motivations that may not provide direct reward but are rather transformed into a form of self-regulation.

\section{Knowledge-sharing intentions and behaviour}

The theory of reasoned action (TRA) (Fishbein and Ajzen, 1975) and the theory of planned behaviour (TPB) (Ajzen, 1991) state that attitudes and beliefs towards certain behaviour affect the development of intentions to perform that behaviour. Individuals may then make a decision to perform it. In this study, we apply this logic of intentions affecting behaviour. Differentiating between individual expectations and actions is also in line with the U\&G approach (Katz et al., 1974), according to which the assumed benefits shape individuals' use of certain media. In recent years researchers have applied the U\&G approach in order to further understanding of user participation, for example, in online customer environments (Nambisan and Baron, 2007; 2009).

Our focus is on knowledge-sharing intentions and knowledge-sharing behaviour. Intentions are understood as an individual's specific purpose in performing an action or set of actions, and behavioural intentions imply that a person is likely to behave in a specific way (Casaló et al., 2010). It also seems that intentions correlate closely with real behaviours (ibid.).

Earlier research on OCs has shown knowledge-sharing behaviour to be significantly dependent on individual motivations (Jeppesen and Frederiksen, 2006; Roberts et al., 2006; Wasko and Faraj, 2000) and expected benefits (Nambisan and Baron, 2007; 2009) as well as attitudes towards knowledge sharing (Hsu et al., 2007) such as the willingness to trust other members. In this study, we test the relationship between knowledge-sharing attitudes (propensity to trust), motivation, and actual knowledge-sharing behaviour.

\section{Research model}

The relationship between propensity to trust and willingness to trust is well-established in existing research (Colquitt et al., 2007; Rotter, 1967), and some researchers view trust as a behavioural intention (Mayer et al., 1995). According to Ridings et al. (2002), in online settings members are typically posting to a general audience rather than to certain individuals. Therefore, trust is at a generalized, collective level instead of taking an interpersonal form. It is based on individual perceptions of the collective and its competence in dealing with the group's purpose or current topic, and the general trustworthiness of other members (Järvenpää et al., 1998; Ridings et al., 2002). We suggest that such generalized trust may play a vital role in determining whether users intend to engage in idea crowdsourcing initiatives or withdraw from sharing their ideas openly. Therefore, we hypothesize:

Hypothesis 1: Propensity to trust has a positive effect on the individual's intention to share knowledge.

Prior studies of OCs have found intrinsic motivation to be an important driver of intentions to contribute knowledge, as people are generally voluntary members of the community and acting on their own behalf. They are likely to have a high degree of autonomy and self- 
determination (Roberts et al., 2006) and work independently of the hosting organization (Wu and Fang, 2010).

Zheng et al. (2011) have studied crowdsourcing with a focus on intentions to participate in crowdsourcing contests, and their study also explicitly addressed intrinsic motivation. The main finding was that intrinsic motivation has a significant effect, underlining the importance of subjective experiences, enjoyment, curiosity and challenging individual intellectual boundaries. In other words, Zheng et al. (2011) emphasized the role of cognitive/learning benefits alongside hedonic ones. However, Brabham (2010) has also pointed out how, on the crowdsourcing site Threadless.com, participation was mostly driven by 'love of community', in other words, the benefits were derived from belonging to the social collective. As Brabham notes, intrinsic motivation plays a significant role, even if its components vary; there is no single list of motivation factors that would cover each type of crowdsourcing initiatives. Here we adopt the categorization of expected benefits (Katz et al., 1974; Nambisan and Baron, 2009) and hypothesize:

Hypothesis 2a: Expected social benefits have a positive effect on the intention to share knowledge.

Hypothesis 2b: Expected learning benefits have a positive effect on the intention to share knowledge.

Hypothesis 2c: Expected hedonic benefits have a positive effect on the intention to share knowledge.

While prior research acknowledges the importance of intrinsic motivation, it also underlines how participation in OCs is driven by extrinsic motivation such as gaining personal reputation or status (Wasko and Faraj, 2000; Roberts et al., 2006). The more members perceive such opportunities, the more they intend to share knowledge. According to studies on crowdsourcing, typical extrinsic motivation factors preceding sharing intentions are direct compensations such as money or other concrete rewards (Brabham, 2010; Leimeister et al., 2009; Zheng et al., 2011), finding job and career opportunities (Leimeister et al., 2009; Zheng et al., 2011) and building an expert profile or marketing oneself (Leimeister et al., 2009). In OCs hosted by companies, it is important to differentiate between recognition from the company in question and recognition from a peer group of users (Jeppesen and Frederiksen, 2006), as their nature differs. A company may offer prizes or monetary rewards, whereas recognition from peers is typically an appraisal of valuable knowledge and expertise. Hence, we hypothesize:

Hypothesis 3a: Recognition from peers has a positive effect on the individual's intention to share knowledge.

Hypothesis 3b: Recognition from the host company has a positive effect on the individual's intention to share knowledge.

In the preceding sections, we have described how the expected benefits shaping different forms of motivation drive the development of behavioural intentions. Although researchers acknowledge that intentions to share do not necessarily materialize as sharing behaviour owing to, for example, possible misinterpretations or other negative consequences (Kuo and Young, 2008), it is reasonable to assume a positive relationship between them in line with the widely accepted TRA and TPB models (Ajzen, 1991; Fishbein and Ajzen, 1975). Furthermore, prior OC research has also revealed the path from intentions to action. Cásalo et 
al. (2010) found out that intentions to participate in online travel communities resulted in favourable behaviours, such as using certain products or services and recommending the hosting firm to other consumers. Bagozzi and Dholakia (2006) investigated the relationship between group-oriented intentions and participating in joint community interactions, showing a strong positive correlation. We therefore hypothesize:

Hypothesis 4: The intention to share knowledge has a positive effect on an individual's knowledge-sharing behaviour.

Figure 1 depicts the research model applied in the study.

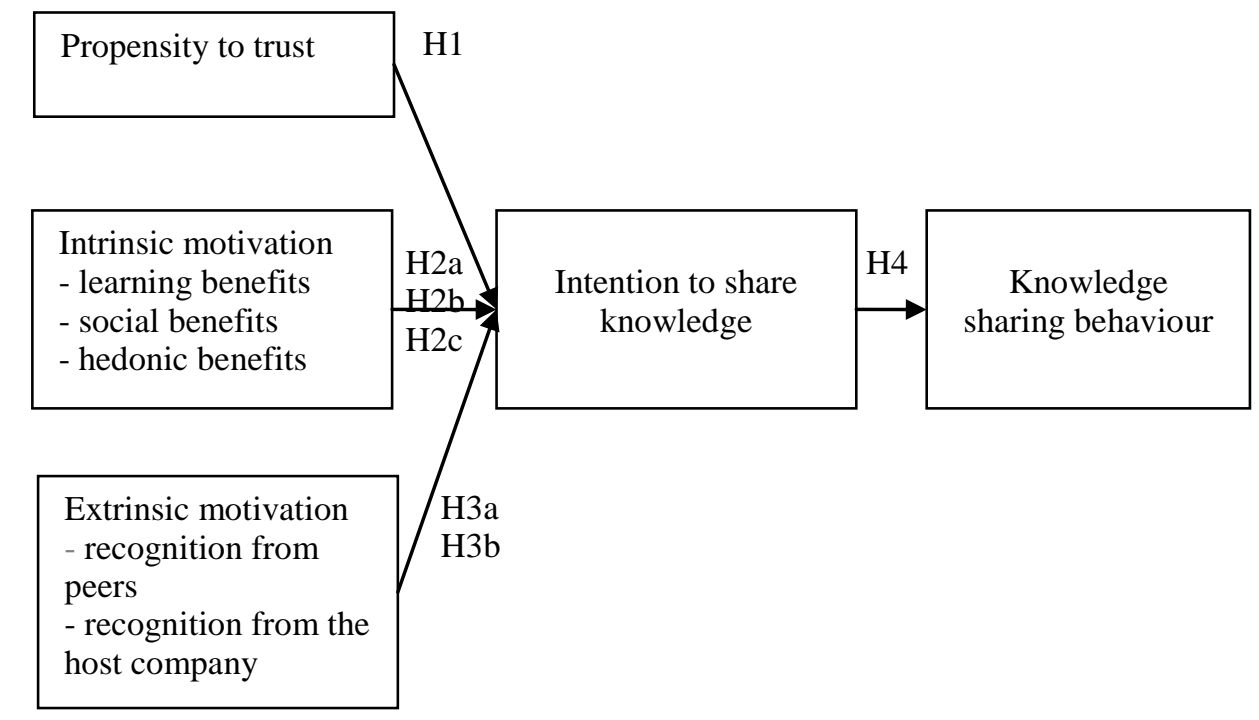

Figure 1. Research model

\section{Research design, methods and data}

\section{Data collection}

To test our hypotheses, we conducted a web-based survey within IdeasProject, an open innovation and brainstorming community dedicated to harvesting ideas. The site is powered and hosted by Nokia, which makes IdeasProject an ideal setting to study company-originated crowdsourcing activities and increase understanding of how to best manage such innovation environments. A significant proportion of the ideas derive from competitions organized by the company (termed "challenges"), but there is also an open idea space serving on 24/7 basis and reflecting the community mode. In both modes, users contribute by suggesting ideas and rating/commenting on ideas given by other users. Typically, users are Nokia brand enthusiasts who also have a lot of experience of the firm's products.

At the time the survey was conducted, the global IdeasProject had operated for around one and a half years and the Chinese version of the site for less than a year. The online survey was conducted in a professional Chinese survey platform, Sojump, from 23 February, 2012 to 7 
April, 2012. An invitation with a hyperlink to the survey questionnaire was incorporated into one challenge project issued in February 2012, and a Chinese microblog was also used by the community manager to invite potential users. A total of 283 users participated in the survey. Incomplete questionnaires could not be submitted successfully, but 39 responses were discarded because respondents had chosen the same answers for all or most of the questions (greater than $83.3 \%$ of them). We considered them to be invalid responses for two reasons. Firstly, they responded in a same way to both negative and positive items. Secondly, the responses were too homogeneous, as if they had systematically answered all questions in the same way. The final effective sample size was 244 . Table 1 presents the demographic information on respondents.

Table 1. Demographic information

\begin{tabular}{|c|c|c|c|c|c|c|c|}
\hline measures & items & frequency & percent (\%) & measures & items & frequency & percent (\%) \\
\hline \multirow[t]{2}{*}{ gender } & male & 205 & 84.0 & \multirow[t]{5}{*}{ age } & $<18$ & 24 & 9.8 \\
\hline & female & 39 & 16.0 & & $18-22$ & 91 & 37.3 \\
\hline \multirow[t]{7}{*}{$\begin{array}{l}\text { member } \\
\text { duration }\end{array}$} & $\begin{array}{l}\text { less than } 1 \\
\text { month }\end{array}$ & 178 & 73.0 & & $23-28$ & 90 & 36.9 \\
\hline & 1 month & 12 & 4.9 & & $29-35$ & 31 & 12.7 \\
\hline & 2-3 months & 12 & 4.9 & & $36-45$ & 8 & 3.3 \\
\hline & 3-4months & 10 & 4.1 & \multirow{4}{*}{$\begin{array}{l}\text { frequency } \\
\text { of logging } \\
\text { into } \\
\text { IdeasProject }\end{array}$} & less & 160 & 65.6 \\
\hline & 4-5 months & 11 & 4.5 & & monthly & 29 & 11.9 \\
\hline & $\begin{array}{l}6 \text { months or } \\
\text { more }\end{array}$ & 21 & 8.6 & & weekly & 40 & 16.4 \\
\hline & & & & & daily & 15 & 6.1 \\
\hline
\end{tabular}

\section{Measurement}

Appendix 1 shows all items for the variables and their sources. Gender, age and membership duration were included as control variables.

The survey instrument was originally created in English and translated into Chinese, and then checked to assure the consistency of the translation. All the items were measured by a 7-point Likert scale, with anchors ranging from strongly disagree (1), neither agree nor disagree (4), to strongly agree (7). We undertook pre-testing of the questionnaire to ensure content validity. Four Chinese master's degree students with experience of participating in OCs were invited to give feedback on the initial questionnaire, by assessing its contextual relevance, clarity and wording. In addition, the host firm's Chinese employees (responsible for local crowdsourcing activities and being involved in the community) commented on the questionnaire. The scale items are shown in Table 2.

The data relied on self-report measures, and therefore common method variance could have biased the findings. Common method bias is of particular concern when survey respondents are asked to address items covering both independent and dependent variables. We used Harman's one-factor test (Podsakoff et al., 2003) to assess the risk of such bias, and conducted a principal component analysis that incorporated all the items from all of the constructs. We investigated the solution in order to determine the number of factors required 
to account for the variance in all the items. The largest factor accounted for 20.6 per cent, which suggests that common method bias was not a concern.

\section{Validity and reliability}

We conducted exploratory factor analysis using principal component analysis and Varimax rotation to test the dimensionality of both the intrinsic and extrinsic motivation. Our results show that intrinsic motivation can be divided into three sub-dimensions (learning, social and hedonic benefits) and extrinsic motivation into two sub-dimensions (recognition from peers and from the host company). As shown in Table 2, all factor loadings are greater than .40, which is the minimum loading required with a sample size of 200 so that the factor loadings are statistically significant (Hair et al., 2006, p. 128). The values of the KMO measure of sampling adequacy exceed the acceptable level (.500)

Table 2. Factor loadings

\begin{tabular}{|c|c|c|}
\hline construct & items & factor loadings ${ }^{a}$ \\
\hline \multirow{2}{*}{$\begin{array}{l}\text { Intrinsic motivation } \\
\mathrm{b}\end{array}$} & IML1: get valuable knowledge. & .839 \\
\hline & IML2: enhance my knowledge about products and services. & .827 \\
\hline $\begin{array}{l}\text { - learning benefits } \\
\text { (IML) }\end{array}$ & IML3: obtain solutions to problems. & .795 \\
\hline \multirow{2}{*}{$\begin{array}{l}\text { - social benefits } \\
\text { (IMS) }\end{array}$} & IMS1: be able to help other people. & .840 \\
\hline & IMS2: enhance my sense of belongingness with this community. & .791 \\
\hline \multirow{2}{*}{$\begin{array}{l}\text { - hedonic benefits } \\
\text { (IMH) }\end{array}$} & IMH1: stimulate my mind. & .860 \\
\hline & $\begin{array}{l}\text { IMH2: derive enjoyment from problem-solving, idea generation, } \\
\text { and so on. }\end{array}$ & .820 \\
\hline \multirow{3}{*}{$\begin{array}{l}\text { Extrinsic } \\
\text { motivation }^{c} \\
\text { - recognition from } \\
\text { peers (RP) }\end{array}$} & RP1: reinforce my credibility in the community. & .881 \\
\hline & $\mathrm{RP} 2$ : receive recognition from peer members. & .864 \\
\hline & $\begin{array}{l}\text { RP3: other solvers to find out how good I really can be in solving } \\
\text { problems. }\end{array}$ & .766 \\
\hline \multirow{2}{*}{$\begin{array}{l}\text { - recognition from } \\
\text { host companies } \\
\text { (RC) }\end{array}$} & $\mathrm{RC} 1$ : receive recognition from Nokia. & .905 \\
\hline & RC2: win an award. & .852 \\
\hline
\end{tabular}

Table 3 presents the Cronbach's alpha reliability coefficients for the scales. Cronbach's alpha values exceed the recommended level of 0.60 for all constructs other than propensity to trust (.557).

Table 3. Mean, SD and correlation matrix

\begin{tabular}{lcccccccccc}
\hline & Mean & $S D$ & KSB & ISK & PTR & IMS & $I M L$ & $I M H$ & $R P$ & $R C$ \\
\hline KSB & 4.706 & 1.245 & .833 & & & & & & \\
ISK & 5.166 & 1.312 & $.766^{* *}$ & .866 & & & & \\
\hline
\end{tabular}




\begin{tabular}{|c|c|c|c|c|c|c|c|c|c|c|}
\hline PTR & 3.924 & 1.169 & $.203^{* *}$ & $.281^{* *}$ & .557 & & & & & \\
\hline IMS & 5.045 & 1.271 & $.431^{* *}$ & $.567^{* *}$ & $.361^{* * *}$ & .810 & & & & \\
\hline IML & 5.523 & 1.266 & $.397^{* *}$ & $.540^{* *}$ & $.240^{* *}$ & $.709^{* * *}$ & .916 & & & \\
\hline IMH & 5.178 & 1.353 & $.296^{* *}$ & $.403^{* *}$ & $.301^{* *}$ & $.598^{* *}$ & $.649^{* *}$ & .819 & & \\
\hline $\mathrm{RP}$ & 4.881 & 1.257 & $.442^{* *}$ & $.477^{* * *}$ & $.272^{* *}$ & $.699^{* * *}$ & $.648^{* * *}$ & $.642^{* * *}$ & .859 & \\
\hline $\mathrm{RC}$ & 5.199 & 1.398 & $.394^{* *}$ & $.491^{* *}$ & $.342^{* *}$ & $.613^{* *}$ & $.631^{* *}$ & $.514^{* * *}$ & $.581^{* *}$ & .826 \\
\hline
\end{tabular}

\section{Data analysis and results}

\section{Correlation analysis}

Table 3 shows the means, standard deviations (SD) and the correlation matrix. There were significant correlations between the independent variables and dependent variables, which indicated that we would be wise to conduct further regression analysis.

\section{Regression analysis}

Hierarchical linear regression analysis was used to test the hypotheses. The standardized regression coefficients and model fit statistics are presented in Tables 4 and 5. Table 4 shows the analyses related to hypotheses $\mathrm{H} 1, \mathrm{H} 2 \mathrm{a}, \mathrm{H} 2 \mathrm{~b}, \mathrm{H} 2 \mathrm{c}, \mathrm{H} 3 \mathrm{a}$ and $\mathrm{H} 3 \mathrm{~b}$, while Table 5 presents the analyses of hypothesis H4. In the first model, only the control variables were entered into the analysis, and the hypothesized independent variable was added individually in the later models.

Table 4 indicates that social benefits (IMS, $\beta=.273, \mathrm{p}<.01$ ) and learning benefits (IML, $\beta=$ $.225, \mathrm{p}<.01$ ) have a significant effect on intention to share knowledge, thus supporting hypotheses $\mathrm{H} 2 \mathrm{a}$ and $\mathrm{H} 2 \mathrm{~b}$. There is also a relationship between recognition from the host company (RC) and intention to share knowledge $(\beta=.143, \mathrm{p}<.10)$, thereby supporting hypothesis $\mathrm{H} 3 \mathrm{~b}$. However, propensity to trust $(\mathrm{H} 1)$, hedonic benefits $(\mathrm{H} 2 \mathrm{c})$, and recognition from peers (H3a) had no significant effect on intention to share knowledge.

Table 4. Regression models (dependent variable: intention to share knowledge)

\begin{tabular}{|c|c|c|c|c|c|c|c|}
\hline & Model 1 & Model 2 & Model 3 & Model 4 & Model 5 & Model 6 & Model 7 \\
\hline & $\beta$ (Sig.) & $\beta$ (Sig.) & $\beta$ (Sig.) & $\beta$ (Sig.) & $\beta$ (Sig.) & $\beta$ (Sig.) & $\beta$ (Sig.) \\
\hline \multicolumn{8}{|c|}{ Control variables } \\
\hline Age & $-.068(.296)$ & $-.085(.173)$ & $-.019(.725)$ & $-.016(.766)$ & $-.015(.771)$ & $-.013(.808)$ & -.007 \\
\hline
\end{tabular}




\begin{tabular}{|c|c|c|c|c|c|c|c|}
\hline & & & & & & & $(.899)$ \\
\hline Member duration & $.002(.972)$ & $-.024(.701)$ & $.013(.815)$ & $-.003(.950)$ & $-.003(.951)$ & $-.005(.919)$ & $\begin{array}{l}-.022 \\
(.671)\end{array}$ \\
\hline Gender (dummy) & $-.004(.949)$ & $-.005(.932)$ & $.029(.581)$ & $.042(.424)$ & $.041(.433)$ & $.034(.527)$ & $.033(.536)$ \\
\hline \multicolumn{8}{|c|}{ Independent variables } \\
\hline PTR & & $\begin{array}{l}.288 * * * \\
(.000)\end{array}$ & $.088(.129)$ & $.094 *(.094)$ & $.095 *(.096)$ & $.095 *(.094)$ & $.077(.179)$ \\
\hline IMS & & & $\begin{array}{l}.536 * * * \\
(.000)\end{array}$ & $\begin{array}{l}.333 * * * \\
(.000)\end{array}$ & $\begin{array}{l}.334 * * * \\
(.000)\end{array}$ & $\begin{array}{l}.302 * * * \\
(.000)\end{array}$ & $\begin{array}{l}.273 * * \\
(.002)\end{array}$ \\
\hline IML & & & & $\begin{array}{l}.283^{* * * *} \\
(.000)\end{array}$ & $\begin{array}{l}.285^{* * * *} \\
(.000)\end{array}$ & $\begin{array}{l}.270 * * \\
(.001)\end{array}$ & $\begin{array}{l}.225^{* *} \\
(.008)\end{array}$ \\
\hline $\mathrm{IMH}$ & & & & & $-.004(.955)$ & $-.029(.701)$ & $\begin{array}{l}-.035 \\
(.642)\end{array}$ \\
\hline $\mathrm{RP}$ & & & & & & $.082(.312)$ & $.058(.475)$ \\
\hline $\mathrm{RC}$ & & & & & & & $\begin{array}{l}.143 * \\
(.051)\end{array}$ \\
\hline \multicolumn{8}{|l|}{ Model summary } \\
\hline $\mathrm{R}^{2}$ & .005 & .087 & .330 & .369 & .369 & .372 & .382 \\
\hline$\Delta \mathrm{R}^{2}$ & & .082 & .243 & .039 & .000 & .003 & .010 \\
\hline $\mathrm{F}$ & .367 & $5.668 * * *$ & $23.418 * * *$ & $23.105 * * *$ & $19.722 * * *$ & $17.387 * * *$ & $16.070 * * *$ \\
\hline$\Delta \mathrm{F}$ & & $21.476 * * *$ & $86.323 * * *$ & $14.769 * * *$ & .003 & 1.027 & $3.847 *$ \\
\hline
\end{tabular}

Note: $* * *<.001 ; * *<.01 ; *<.10$

Table 5 displays the relationship between intention to share knowledge and knowledgesharing behaviour. We can see that Hypothesis 4 is supported $(\beta=.768, p<.001)$.

Table 5. Regression models (dependent variable: knowledge-sharing behaviour)

\begin{tabular}{lll}
\hline & Model 1 & Model 2 \\
& $\beta$ (Sig.) & $\beta$ (Sig.) \\
\hline Control variables & & \\
Age & $-.016(.804)$ & $.036(.387)$ \\
Member duration & $.027(.671)$ & $.026(.535)$ \\
Gender (dummy) & $.075(.248)$ & $.078(.061)$ \\
& & \\
\hline
\end{tabular}




\begin{tabular}{lll}
\hline ISK & $.768^{* * *}(.000)$ \\
Model summary & & \\
$\mathrm{R}^{2}$ & .007 & .594 \\
$\Delta \mathrm{R}^{2}$ & & .587 \\
$\mathrm{~F}$ & .560 & $87.444^{* * *}$ \\
$\Delta \mathrm{F}$ & & $345.685^{* * *}$ \\
\hline Note: $* * *<.001$. &
\end{tabular}

\section{Discussion}

\section{Summary and implications}

Idea crowdsourcing offers firms the opportunity to involve a large body of users in innovation activities. Companies such as IBM, Nokia and Dell have engaged in soliciting voluntary users' input online. However, as noted by Füller et al. (2008), the mere existence of a favoured brand hosting an innovation platform is not enough to promote active knowledge sharing. It is rather the interest of individual users and their expectations that drive participation and engagement. As users play a major role in terms of developing new ideas or designs, unravelling the individual expectations and motivations remains a focal issue for both researchers and practicing managers.

Existing research has acknowledged the importance of studying users' motivation to participate in innovation activities online (Jeppesen and Frederiksen, 2006; Nambisan and Baron, 2007; Zheng et al., 2011). While there are already bodies of research concerning user motivation in OCs (e.g. Wasko and Faraj, 2000; Bagozzi and Dholakia, 2006, Jeppesen and Frederiksen, 2006) and employee participation in creative activities (see e.g. Zhou and Shalley, 2003 for a review), less effort has been dedicated to voluntary users engaging in idea crowdsourcing online, partly due to the novelty of the phenomenon. Our paper is among the first to attempt to understand the relationship between motivations and knowledge sharing in idea crowdsourcing. Its findings will be important to companies hosting crowdsourcing platforms and other types of open innovation environments, where the aim is to develop more appealing products or services and to increase levels of user activity in creating more innovative outputs. From the hosting company's point of view, there are basically three modes of crowdsourcing implementation: communities, contests, and events. These can be further distinguished by whether they are organized by the company itself or by third-party intermediaries (see Figure 2). 


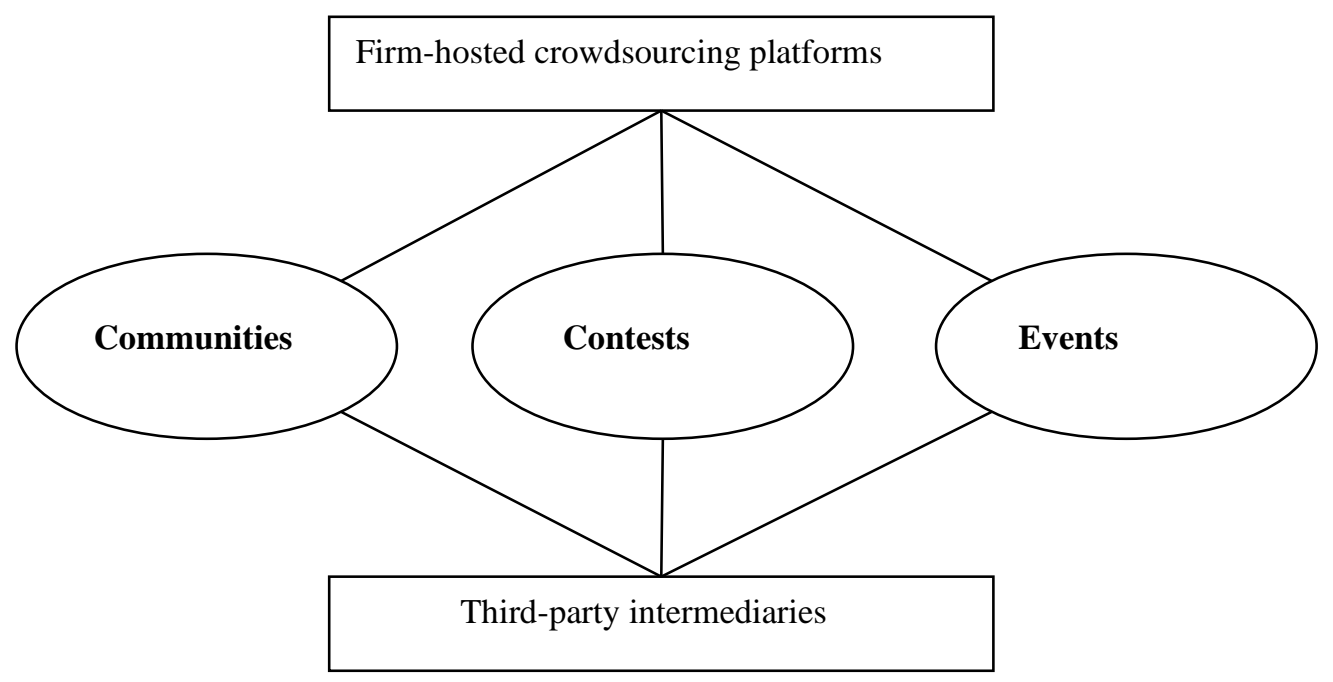

Figure 2. Modes of crowdsourcing.

In our view, IdeasProject represented a hybrid form displaying traits from both firm-hosted OCs and temporary innovation contests. Communities are dedicated to developing better products or services on an ongoing basis (Bayus, 2013; Nambisan and Baron, 2007; Jeppesen and Frederiksen, 2006), whereas in contests there is an open call focusing on a specific temporary task or problem (Zheng et al., 2011; Jeppesen and Lakhani, 2010). As far as we know, our setting is unique as research on community-contest combinations of open innovation activities is scarce (see Hutter et al., 2011 and Bayus, 2013 as exceptions). In addition to investigating this hybrid mode of crowdsourcing, our study makes several important contributions, which we detail below.

First, our study underlines the role of expected benefits in shaping user behaviour. As noted by Nambisan and Baron (2009), a continuing dedicated participation online is unlikely to be driven only by norm-related tendencies or a general satisfaction gained from being able to help others (see also Risom Jespersen, 2011). Instead, users expect some kind of benefit which then influences their future behaviour. We contribute to the innovation management literature by bringing this discussion based on the U\&G approach to the novel context of idea crowdsourcing. Following the path set up by Nambisan and Baron $(2007 ; 2009)$, we adopted several categories of benefits - cognitive/learning, hedonic, social integrative, and personal integrative - instead of focusing only a certain type in order to understand knowledge-sharing behaviour.

Second, our research shows that the key driver of knowledge-sharing intentions is made up of two intrinsic motivations - social integrative benefits and learning benefits. The relative importance of the social integrative benefits calls for better facilities available for users to be able to help each other in formulating and developing their ideas. Probably the most typical solutions applied for such purpose are ratings (such as "like" -features or "thumbs up" indications) or comments, but crowdsourcing platforms could benefit from establishing richer means for user-to-user interactivity, such as messaging systems and discussion spaces. Users could also form specific task groups among users who have similar interests and ideas, as narrower topic groups provide more opportunities for cohesiveness than is possible among a 
large mass of users with diverse backgrounds and varying knowledge bases. Learning and creativity, in turn, could be inspired by encouraging feedback from professionals and experts, while providing insight into technological advances and features dealing with the topic of the current task, for example. To our understanding, all the proposed solutions would help the hosting organization to improve the quality of ideas suggested by users through increased interaction and collaboration. A more competitive approach - establishing idea contests in order to find a winning solution to be rewarded (Zheng et al., 2011) - would likely result in the increased quantity of ideas. It is thus a strategic decision of the hosting organization to position itself along the continuum of collaboration-based or competition-based crowdsourcing (Afuah and Tucci, 2012) based on the targeted objective, either better quality or higher quantity of user input. As Hutter et al. (2011) noted, the best option in terms of idea quality may be 'communitition', that is, collaboration among users who simultaneously compete with each other. The study advises managers to try to identify such communititors among the larger crowd. In terms of our study, special attention should thus be paid to users whose sharing behaviour is driven simultaneously by the social integrative and personal integrative (e.g. gaining recognition) types of benefits.

Third, we found that recognition from the host company indeed affects the intention to share knowledge. This is in line with the findings by Jeppesen and Frederiksen (2006), while other studies on company-hosted OCs have largely neglected the role of company-user feedback and interactions. One possible explanation is that many existing studies have focused on rather "tight" communities (Cásalo et al., 2010; Wu and Fang, 2010; Sawhney et al., 2005), involving higher degrees of social interaction and reciprocity among peers than are typically present in idea crowdsourcing. In addition, OCs are traditionally seen as collaborative, whereas crowdsourcing in its most typical form is competitive (Afuah and Tucci, 2012). Findings from OC research - or research adopting an employee's perspective, for that matter - may thus not be fully compatible with settings where voluntary users contribute to a task involving participants they do not know, and where those users may compete with each other to gain rewards. It is also noteworthy that social-interaction patterns or collaborative practices may not have become established in the early stages of site lifecycle, as it was the case with IdeasProject. In that early stage, it can be assumed that the role of the company in helping the site to thrive would be accentuated.

The relative importance of company recognition implies that there is a need to dedicate sufficient company resources to management and bringing the hosting firm closer to individual users online. An existing user community of brand/product enthusiasts - which is a common denominator for many online-community members as well - is a valuable resource that needs to be taken good care of. This calls for a wider set of means affording active contributors more visibility, but also for shorter response times regarding user input. Our study reinforces that material rewards are not quintessential here, and in fact may even become counterproductive (see also Bock and Kim, 2002), whereas "soft" rewards such as granting time, attention and taking care of a contributor can be productive. Nambisan and Baron (2009) note the apparent tendency of firms to establish online platforms based on the idea that "when we build it, customers will come" and support each other on a continuous basis. The approach has two pitfalls: first, users only act based on the benefits they expect, and secondly, such benefits cannot be realized without additional resourcing and investment by the company.

We also found that propensity to trust did not play a role in knowledge-sharing intentions. This is in line with Ridings et al. (2002), in whose work trust propensity only affected the perceived trust towards other OC members but not the giving of information. Here we must 
also note the deficiencies in measuring propensity to trust, that recorded a low reliability value (.557), suggesting the need for further development.

Finally, an interesting finding was that hedonic benefits were not significant for establishing knowledge-sharing intentions. We suspect that the expected benefits could be mutually exclusive to some degree. In practice-oriented communities where users expect to reinforce their social networks, help others and acquire new knowledge, hedonic benefits such as enjoyment and mental-stimulation may turn out to be less important. Another possible explanation could be the way the site is designed, which refers back to its purpose. As many of the ideas provided concern mobile technologies, the site may reflect a certain "solutioncenteredness" driven to develop ideas for better products and services rather than providing mere fun and enjoyment. Again, the type of the innovation environment concerned determines the benefits users may expect.

\section{Limitations and future research}

An obvious limitation of our study is that we collected data only from Chinese site of IdeasProject, meaning that a wider generalization across other types of online innovation environments or cultural contexts should be done with caution. However, we believe that the current study wins its target in making the phenomenon more understandable and helping to build further U\&G based initiatives for studying idea crowdsourcing. In particular, we encourage future research on expected benefits and how they shape user behaviour. For instance, it would be valuable to compare expected benefits of users based on their cultural backgrounds or membership lifecycle. Also within IdeasProject, it would be valuable to compare users' motivations based on their cultural background, as it is a global site consisting of different user groups.

Based on the lessons learned, we suggest that in further studies researchers could differentiate between the individual general propensity to trust, social trust in other specific users, and trust in the hosting organization. A general propensity to trust could differ across national cultures. Social trust in other specific users would signal individual users' experience of other users' competence and goodwill. Finally, if businesses are to establish online environments to support product development, trust in the hosting organization remains an understudied area that merits more attention. We noted that a site provider has an important role in both enabling innovative users to gather together and in motivating participation by granting them recognition.

In their recent study, Afuah and Tucci (2012) note how further research needs to investigate the conditions under which it is beneficial to make users compete with each other in crowdsourcing initiatives rather than collaborate, and vice versa. We believe there is also a need to better understand the hybrid forms of crowdsourcing - as there was in the case of IdeasProject - where the same crowdsourcing platform is applied in both a competitive and a collaborative manner, depending on the task at hand. Further studies on user behaviour and knowledge sharing patterns, perhaps relying on comparative cases for example, are therefore warranted. ,. In this manner, researchers and practitioners could better outline which types of tasks or problems favour collaborative behaviour, and which types of tasks are better suited to contests. 
Regarding the limitations of our study, it is noteworthy that a significant proportion of respondents $(73 \%)$ had been members of IdeasProject for only a month or less, an effect of the site existing for less than a year at the time. We are aware that the limited number of idea contests that had been held at the time of our survey may have meant that the type of ideas concerned affected the expected benefits. Further research should thus be conducted when the community and membership is more mature, and the types of benefits underlying motivation to participate could be explicitly tied to the task in question.

Nevertheless, we believe that our results provide important insights into what newcomers value in organization-hosted crowdsourcing platforms. The elements valued are indeed the social ties and opportunities to learn new things rather than concrete awards or esteem. That appears to be the case even before the participants have learned much about the site. This notion of the importance of intrinsic motivation is not new in OCs where voluntary users have long gathered together around a shared interest to produce public goods for free (Hars and $\mathrm{Ou}$, 2002; Wasko and Faraj, 2000). Yet it might still be new for some hosting companies with a different culture, where all work is paid for. An interesting subtlety in firm-hosted crowdsourcing platforms is the presence of members taking a challenging dual role as both user and firm employee. Often these members also contribute to the selection and development of user ideas, and in that way they act as community gatekeepers. To turn the idea creators' best input into concrete action - products and services - would necessitate further investigation of the role of community gatekeepers and their effort in evaluating the ideas elicited from voluntary online crowds.

\section{References}

Afuah, A. and Tucci, C.L. (2012 'Crowdsourcing as a solution to distant search', Academy of Management Review, Vol. 37, No. 3, pp. 355-375.

Ajzen, I. (1991) 'The theory of planned behaviour', Organizational Behavior and Human Decision Process, Vol. 50, pp. 179-211.

Bagozzi, R.P. and Dholakia, U.M. (2006) 'Open Source Software User Communities: A Study of Participation in Linux User Groups', Management Science, Vol. 52, No. 7, pp. 10991115 .

Bock, G. and Kim, Y-G. (2002) 'Breaking the myth of rewards: An exploratory study of attitudes about knowledge sharing', Information Resources Management Journal, Vol. 15, No. 2, pp. 14-21.

Brabham, D.C. (2010) 'Moving the crowd at Threadless. Motivations for participation in a crowdsourcing application', Information, Communication \& Society, Vol. 13, No. 8, pp. 1122-1145.

Cásalo, L.V., Flavián, C. and Guinalíu, M. (2010) 'Determinants of the intention to participate in firm-hosted online travel communities and effects on consumer behavioral intentions', Tourism Management, Vol. 31, pp. 898-911.

Chesbrough, H. (2003) Open Innovation: The New Imperative for Creating and Profiting from Technology. Boston, MA: Harvard Business School Press. 
Deci, E.L. and Ryan, R.M. (2000) 'The "what" and "why" of goal pursuits: Human needs and the self-determination of behaviour', Psychological Inquiry, Vol. 11, No. 4, pp. 227-268.

Colquitt J.A., Brent A.S. and LePine J.A. (2007) 'Trust, Trustworthiness, and Trust Propensity: A Meta-Analytical Test of Their Unique Relationships With Risk Taking and Job Performance', Journal of Applied Psychology, Vol. 92, No. 4, pp. 909-927.

Dietz, G., Gillespie N. and Chao, G. (2010) 'Unravelling the complexities of trust and culture', in Saunders, M., Skinner, D., Gillespie, N., Dietz, G. and Lewicki, R. (Eds.) Organisational Trust: A Cultural Perspective, Cambridge Companions to Management, Cambridge: Cambridge University Press, pp. 3-41.

Faraj, S., Jarvenpaa, S.L. and Majchrzak, A. (2011) 'Knowledge Collaboration in Online Communities’, Organization Science, Vol. 22, No. 5, pp. 1224-39.

Fishbein, M., and Ajzen, I. (1975) Belief, Attitude, Intention, and Behavior: An Introduction to Theory and Research. Reading, MA: Addison-Wesley.

Fuchs, C. and Schreier, M. (2011) 'Customer Empowerment in New Product Development', Journal of Product Innovation Management, Vol. 28, pp. 17-32.

Füller, J., Bartl, M., Ernst, H. and Mühlbacher, H. (2006) 'Community based innovation: How to integrate members of virtual communities into new product development', Electronic Commerce Research, Vol. 6, pp. 57-73.

Füller, J., Matzler, K. and Hoppe, M. (2008) 'Brand Community Members as a Source of Innovation', Journal of Product Innovation Management, Vol. 25, pp. 608-619.

Hair, J. F., Black, W. C., Babin, B. J., Anderson, R. E., and Tatham, R. L. (2006) Multivariate Data Analysis - 6th edition. New Jersey: Pearson Education.

Hars, A. and Ou, S. (2002) 'Working for free? Motivations for participating in open-source projects', International Journal of Electronic Commerce Vol. 6, No. 3, pp. 25-39.

Hertel, G., Niedner, S. and Herrmann, S. (2003) 'Motivation of software developers in open source projects: An Internet-based survey of contributors to the Linux kernel', Research Policy Vol. 32, pp. 1159-1177.

Hofstede, G. (1991) Culture and Organizations: Software of the Mind. London: McGraw Hill.

Howe, J. (2008) Crowdsourcing: why the power of the crowd is driving the future of business. New York: Crown Business.

Hsu, M-H., Ju, T., Yen, C-H. and Chang, C-M. (2007) 'Knowledge sharing behavior in virtual communities: The relationship between trust, self-efficacy, and outcome expectations', International Journal of Human-Computer Studies, Vol. 65, pp. 153-169.

Hutter, K., Hautz, J., Füller, J., Mueller, J. and Matzler, K. (2011) 'Communitition: The Tension between Competition and Collaboration in Community-Based Design Contests', Creativity and Innovation Management, Vol. 20, No. 11, pp. 3-21.

Jawecki, G., Füller, J. And Gebauer, J. (2011) 'A Comparison of Creative Behaviours in Online Communities across Cultures', Creativity and Innovation Management, Vol. 20, No. 3, pp. 144-156. 
Jeppesen, L.B. and Frederiksen, L. (2006) 'Why Do Users Contribute to Firm-Hosted User Communities? The Case of Computer-Controlled Music Instruments', Organization Science, Vol. 17, No. 1, pp. 45-63.

Jeppesen, L. and Lakhani, K.R. (2010) 'Marginality and Problem-Solving Effectiveness in Broadcast Search', Organization Science, Vol. 21, No. 5, pp. 1016-33.

Järvenpää, S.L. Knoll, K. and Leidner D.E. (1998) 'Is Anybody Out There? Antecedents of Trust in Global Virtual Teams', Journal of Management Information Systems, Vol. 14, No. 4, pp. 29-64.

Katz, E., Blumler, J.G. and Gurevitch, M. (1974) 'Utilization of Mass Communication by the Individual', in Blumler, J.G. and Katz, E. (Eds.) The Uses of Mass Communications: Current Perspectives on Gratifications Research, Beverly Hills: Sage Publications, pp. 19-32.

Kuo, F-Y. and Young, M-L. (2008) 'Predicting knowledge sharing practices through intention: A test of competing models', Computers in Human Behavior, Vol. 24, No. 6, pp. 2697-2722.

Leimeister, J.M., Huber, M., Bretschneider, U., and Kremar, H. (2009) 'Leveraging Crowdsourcing: Activation-Supporting Components for IT-Based Ideas Competition', Journal of Management Information Systems, Vol. 26, No. 1, pp. 197-224.

Mayer, R., Davis, J. and Schoorman, D. (1995) 'An integrative model of organizational trust', Academy of Management Review, Vol. 23, No. 3, pp. 473-490.

McKnight, D., Cummings, L. and Chervany, N. (1998) 'Initial trust formation in new organizational relationships', Academy of Management Review, Vol. 23, No. 3, pp. 473-490.

Mitchell, T.R. and Daniels, D. (2003) 'Motivation', Handbook of Psychology. Industrial and Organizational Psychology, Vol. 12, pp. 225-254. New York: Wiley.

Nambisan, S. and Baron, R.A. (2007) 'Interactions in virtual customer environments: Implications for product support and customer relationship management', Journal of Interactive Marketing, Vol. 21, No. 2, pp. 42-62.

Nambisan, S. and Baron, R.A. (2009) 'Virtual Customer Environments: Testing a Model of Voluntary Participation in Value Co-Creation Activities', Journal of Product Innovation Management, Vol. 26, pp. 388-406.

Podsakoff, P.M., MacKenzie, S.B., Lee, J.-Y. and Podsakoff, N.P. (2003) 'Common Method Biases in Behavioral Research: A Critical Review of the Literature and Recommended Remedies', Journal of Applied Psychology, Vol. 88, pp. 879-903.

Poetz, M.K. and Schreier, M. (2012) 'The Value of Crowdsourcing: Can Users Really Compete with Professionals in Generating New Product Ideas?', Journal of Product Innovation Management, Vol. 29, No. 2, pp. 245-256.

Prahalad, C.K. and Ramaswamy, V. (2000) 'Co-opting customer competence', Harvard Business Review, Vol. 78, No. 1, pp. 79-87.

Ridings, C., Gefen, D. and Arinze, B. (2002) 'Some antecedents and effects of trust in virtual communities’, Journal of Strategic Information Systems, Vol. 11, pp. 271-295. 
Risom Jespersen, K. (2011) 'Online channels and innovation: Are users being empowered and involved?’, International Journal of Innovation Management, Vol. 15, No. 6, pp. 1141-59.

Roberts, J.A., Hann, I.H. and Slaughter, S.A. (2006) 'Understanding the Motivations, Participation, and Performance of Open Source Software Developers: A Longitudinal Study of the Apache Projects', Management Science, Vol. 52, No. 7, pp. 984-999.

Rotter, J.B. (1967) 'A New Scale for the Measurement of Interpersonal Trust', Journal of Personality, Vol. 35, pp. 651-665.

Ryan, M.R., and Deci, L.E. (2000) 'Self-Determination Theory and the Facilitation of Intrinsic Motivation, Social Development, and Well-Being', American Psychologist, Vol. 55, No. 1, pp. 68-78.

Sawhney, M., Verona, G. and Prandelli, E. (2005) 'Collaborating to create: the Internet as a platform for consumer engagement in product innovation', Journal of Interactive Marketing, Vol. 19, No. 4, pp. 4-17.

Simula, H. and Vuori, M. (2012) 'Benefits and barriers of crowdsourcing in B2B firms: generating ideas with internal and external crowds', International Journal of Innovation Management, Vol. 16, No. 6.

Yang, J., Ackerman, M.S. and Adamic, L. (2011) 'Virtual Gifts and Guanxi: Supporting Social Exchange in a Chinese Online Community', CSCW 2011, March 19-23, 2011, Hangzhou, China.

Von Hippel, E. (1988) The Source of Innovation. New York: Oxford University Press.

Von Hippel, E., Ogawa, S. and De Jong, J.P.J. (2011) 'The Age of the Consumer-Innovator', MIT Sloan Management Review, Vol. 53, No. 1, pp. 27-35.

Wasko, M.M. and Faraj, S. (2000) '"It is What One Does": Why People Participate and Help Others in Electronic Communities of Practice', Journal of Strategic Information Systems, Vol. 9, Nos. 2-3, pp. 155-173.

Wasko, M.M. and Faraj, S. (2005) "'Why should I share?" Examing social capital and knowledge contribution in electronic networks of practice', MIS Quarterly, Vol. 29, No. 1, pp. 35-57.

Wiertz, C. and de Ruyter, K. (2007) 'Beyond the call of duty: why customers contribute to firm-hosted commercial online communities', Organization Studies, Vol. 28, No. 3, pp. 347376.

Wu, S.-C. and Fang, W. (2010) 'The effect of consumer-to-consumer interactions on idea generation in virtual brand community relationships', Technovation, Vol. 30, Nos. 11-12, pp. 570-581.

Zheng, H., Li, D. and Hou, W. (2011) 'Task Design, Motivation, and Participation in Crowdsourcing Contests', International Journal of Electronic Commerce, Vol. 15, No. 4, pp. 57-88.

Zhou, J. And Shalley, C.E. (2003) 'Research on employee creativity: a critical review and directions for future research', Research in Personnel and Human Resources Management, Vol. 22, pp. 165-217. 


\section{Appendix 1. Items wording}

\begin{tabular}{|c|c|c|}
\hline construct & items & sources \\
\hline \multirow[t]{2}{*}{ Propensity to trust } & $\begin{array}{l}\text { Most IdeasProject users can be counted to do what they say they } \\
\text { will do. }\end{array}$ & Järvenpää et al., 1998 \\
\hline & $\begin{array}{l}\text { Most users are very competent in terms of their knowledge related } \\
\text { to IdeasProject problems/issues. }\end{array}$ & Järvenpää et al., 1998 \\
\hline \multirow{3}{*}{$\begin{array}{l}\text { Intrinsic motivation } \\
\text { - learning benefits } \\
\text { (IML) }\end{array}$} & get valuable knowledge. & $\begin{array}{l}\text { Wiertz and de Ruyter } \\
(2007)\end{array}$ \\
\hline & enhance my knowledge of products and services. & $\begin{array}{l}\text { Nambisan and Baron } \\
\text { (2007) }\end{array}$ \\
\hline & obtain solutions to problems. & $\begin{array}{l}\text { Nambisan and Baron } \\
(2007)\end{array}$ \\
\hline \multirow{2}{*}{$\begin{array}{l}\text { - social benefits } \\
\text { (IMS) }\end{array}$} & be able to help other people. & Wasko and Faraj (2005) \\
\hline & enhance my sense of belonging with this community. & $\begin{array}{l}\text { Nambisan and Baron } \\
(2007)\end{array}$ \\
\hline \multirow[t]{2}{*}{$\begin{array}{l}\text { - hedonic benefits } \\
\text { (IMH) }\end{array}$} & stimulate my mind. & $\begin{array}{l}\text { Nambisan and Baron } \\
\text { (2007) }\end{array}$ \\
\hline & $\begin{array}{l}\text { derive enjoyment from problem-solving, idea generation, and so } \\
\text { on. }\end{array}$ & $\begin{array}{l}\text { Nambisan and Baron } \\
(2007)\end{array}$ \\
\hline $\begin{array}{l}\text { Extrinsic } \\
\text { motivation }\end{array}$ & reinforce my credibility in the community. & $\begin{array}{l}\text { Nambisan and Baron } \\
(2007)\end{array}$ \\
\hline $\begin{array}{l}\text { - recognition from } \\
\text { peers }(\mathrm{RP})\end{array}$ & receive recognition from peer members. & $\begin{array}{l}\text { Jeppesen and Frederiksen } \\
\text { (2006) }\end{array}$ \\
\hline \multirow{3}{*}{$\begin{array}{l}\text { - recognition from } \\
\text { host companies } \\
\text { (RC) }\end{array}$} & $\begin{array}{l}\text { other problem solvers to find out how good I really can be in } \\
\text { solving problems. }\end{array}$ & Zheng et al. (2011) \\
\hline & receive recognition from Nokia. & Zheng et al. (2011) \\
\hline & win an award. & Zheng et al. (2011) \\
\hline \multirow{2}{*}{$\begin{array}{l}\text { Intention to share } \\
\text { knowledge (ISK) }\end{array}$} & I intend to actively provide ideas. & Cásalo et al. (2010) \\
\hline & I intend to actively provide comments on other members' ideas. & Cásalo et al. (2010) \\
\hline \multirow[t]{3}{*}{$\begin{array}{l}\text { Knowledge sharing } \\
\text { behaviour (KSB) }\end{array}$} & $\begin{array}{l}\text { When discussing a complicated issue, I am usually involved in } \\
\text { subsequent interactions (such as questions and comments). }\end{array}$ & Hsu et al. (2007) \\
\hline & I frequently put forward my ideas. & Cásalo et al. (2010) \\
\hline & I frequently comment on others' ideas. & Cásalo et al. (2010) \\
\hline
\end{tabular}

